\title{
Complete Nucleotide Sequence of the Mitochondrial DNA of Halyomorpha halys (Stal) (Hemiptera: Pentatomidae) Specimens Collected Across Georgia
}

\author{
Mari Gogniashvili*, Nana Kunelauri, Tamar Shanava, Natia Tephnadze, Tengiz Beridze \\ Institute of Molecular Genetics, Agricultural University of Georgia, Tbilisi, Georgia \\ Email: ^m.gogniashvili@agruni.edu.ge
}

How to cite this paper: Gogniashvili, M. Kunelauri, N., Shanava, T., Tephnadze, N. and Beridze, T. (2021) Complete Nucleotide Sequence of the Mitochondrial DNA of Halyomorpha halys (Stal) (Hemiptera: Pentatomidae) Specimens Collected Across Georgia. Advances in Entomology, 9, 113-121. https://doi.org/10.4236/ae.2021.93010

Received: April 5, 2021

Accepted: June 7, 2021

Published: June 10, 2021

Copyright $\odot 2021$ by author(s) and Scientific Research Publishing Inc. This work is licensed under the Creative Commons Attribution International License (CC BY 4.0).

http://creativecommons.org/licenses/by/4.0/

\begin{abstract}
The brown marmorated stink bug, Halyomorpha halys (Stal) (Hemiptera: Pentatomidae) is an invasive species native to East Asia that has spread across Asia, Europe, and North America. H. halys causes damages to various grains, fruits, and vegetables, which is exemplified by the significant damage to the hazelnut harvest in Georgia (during 2016). This report describes the first attempted genetic study of the spread of $H$. halys in Georgia. The first main goal of this research was to identify the haplotype of an invasive population in Georgia. For this purpose, the mitochondrial cytochrome c oxidase I subunit (COI) gene fragment from 65 samples of $H$. halys collected from different regions across Georgia was sequenced on an Applied Biosystems 3100 or 3700 genetic analyzer. In all cases, only the $\mathrm{H} 1$ haplotype, which is native to China, was identified. The second goal of this research was to determine the complete mitochondrial DNA sequence of $H$. halys (Stal) specimens collected across Georgia. The complete mitochondrial DNA of H1 haplotype sequenced on an Illumina MiSeq platform. The mitochondrial DNA of the Georgian H1 haplotype has a length of 15,478 base pairs. Using the sequence of the $\mathrm{H} 22$ haplotype of $H$. halys (native to Korea) as a reference, 62 single nucleotide polymorphisms (SNPs), three inversions, and four single $\mathrm{T}$ insertions were identified. Furthermore, 60 SNPs and four insertions in two tRNA and one rRNA genes were identified among 18 mitochondrial genes from the Georgian $\mathrm{H} 1$ haplotype. Nine of these SNPs resulted in amino acid substitutions. Furthermore, the detection of SNPs revealed many other polymorphic sites beyond the COI gene, which can be used to detect new haplotypes.
\end{abstract}

\section{Keywords}

Halyomorpha halys, Mitochondrial DNA, Illumina, Sequencing, Single 
Nucleotide Polymorphism

\section{Introduction}

Halyomorpha halys (Stal) (Hemiptera: Pentatomidae) is an invasive insect pest that attacks crop species and causes substantial economic damage [1]. This insect family is native to various East Asian countries, including China, Japan, Korea, and Taiwan, where it is treated as a biological enemy and therefore, does not spread uncontrollably. Its rapid diffusion in other continents and the resulting damage of many agricultural crops, have led to global interest in this insect. In North America, $H$. halys is responsible for damages amounting to more than 21 billion dollars [2]. Since its first identification in the United States (US) in 1998, H. halys has spread in 34 states and represents a serious threat to agriculture. In Europe, this species was first identified in Switzerland in 2008. In 2014 it was identified in the Sochi region of Russia following spread from either Italy or Greece during preparations for the 2014 Winter Olympics [3]. In 2015, H. halys spread from Russia to the Abkhazia region of Georgia, and in 2016, these insects began to spread massively in different regions of west Georgia, where they significantly damaged nuts, corn, and citrus crops [4] [5]. By the end of 2017, $H$. halys had also spread to east Georgia.

Identifying the origin of a biological invasion has important implications for the effective control of the invasive species. Xu and colleagues [6] detected high levels of genetic divergence among native populations of $H$. halys and traced the origin of the invasive population in the US to the Beijing area of China. These researchers identified two mitochondrial $H$. halys haplotypes in the US and 43 haplotypes in native populations. In Italy, 20 previously unknown $H$. halys haplotypes were discovered through an analysis of the COI gene in mitochondrial DNA [3]. Another study involved a mitochondrial genome analysis to identify the genetic diversity of $H$. halys. For example, $45 \mathrm{H}$. halys haplotypes were detected in different ecoregions of the US, Europe, and Asia (10 Countries); the Korean $H$. halys populations exhibited the second highest level of diversity among the 10 countries and with only Greece exhibiting higher diversity. Haplotype $\mathrm{H} 22$ was prominent in Korea, $\mathrm{H} 1$ was prominent in China, Greece, Hungary, Italy, Canada, and USA, and $\mathrm{H} 3$ was prominent in France and Switzerland [7]. The identified haplotype diversity patterns revealed that the $H$. halys populations in Korea were genetically distinct from those in China, Europe, and North America. Additionally, the populations in Europe and North America were determined to have arisen through multiple invasions from China. H. halys haplotypes of both Chinese and Korean was spread only in Greece. In contrast, the Japanese haplotype is conserved in Japan and has not been identified elsewhere. According to these findings, only $H$. halys strains that originated from China have spread throughout Europe (with the exception of Greece) and North 
America, whereas the spread of Korean strains has not been observed. Previously, the complete mitochondrial DNA sequence of only one $H$. halys $\mathrm{H} 22$ haplotype (native to Korea) had been determined (GenBank accession number NC_ 013272.1) [8]. Tracing the diffusion modes of species by analyzing the genetic structures and compositions of populations during the initial phase of colonization could enable the implementation of better pest control strategies. Furthermore, the reconstruction of geographical pathways can be used to design strategies for the management and prevention of pest invasions [2].

\section{Materials and Methods}

\subsection{PCR Analyses}

Sixty-five specimens of $H$. halys were collected from the western regions of Georgia, including Guria, Samegrelo, Imereti, Adjara, and Abkhazia. Genomic DNA was extracted from one hind leg of each specimen using a DNeasy Blood \& Tissue Kit (Qiagen, Inc., Dusseldorf, Germany) according to the manufacturer's instructions. A 712 base pare (bp) section of the COI gene was amplified using the primer sequences designed by Folmer and colleagues [9] and modified according to the complete nucleotide sequence of $\mathrm{H} 22$ haplotype mitochondrial DNA (GenBank accession number NC_013272.1) [8]. The primer sequences were as follows: Forward, 5'-ATTCTACTAATCATAAAGATATTGG-3' and Reverse, 5'-TAAACTTCGGGGTGCCCAAAGAATCA-3'. PCR was performed using the following program: initial denaturation at $95^{\circ} \mathrm{C}$ for $5 \mathrm{~min} ; 34$ cycles at $95^{\circ} \mathrm{C}$ for $30 \mathrm{~s}, 45^{\circ} \mathrm{C}-50^{\circ} \mathrm{C}$ for $30 \mathrm{~s}$ and $72^{\circ} \mathrm{C}$ for $30 \mathrm{~s}$; and final extension at $72^{\circ} \mathrm{C}$ for $5 \mathrm{~min}$. The PCR products were analyzed using 1.5\% agarose gel electrophoresis and sequenced on an Applied Biosystems 3100 or 3700 genetic analyzer at the Laboratory Services Division of the University of Guelph (ON, Canada). Consensus files were aligned using Clustal X 1.83 [10]. The new COI sequences generated from the $H$. halys individuals were deposited in GenBank (LC581788LC581792). The Mafft and Blast software programs were used for detection of SNPs and insertions [11] [12].

\subsection{Evolutionary Analysis Using the Maximum Likelihood Method}

The evolutionary history was inferred using the maximum likelihood method and Tamura-Nei model [13]. The tree with the highest log likelihood (-1055.47) is shown (Figure 1). The tree was drawn to scale, with branch lengths indicating the number of substitutions per site. This analysis involved 31 nucleotide sequences and the final dataset included 608 positions in the. Evolutionary analyses were conducted in MEGA X [14].

\subsection{Genomic DNA Library Preparation and Sequencing on an Illumina MiSeq Platform}

Genomic DNA libraries were constructed using the NEBNext Ultra DNA Library Prep Kit for Illumina (New England Biolabs, MA, USA). Genomic DNAs 
were quantified using the Qubit BR reagents (Qubit 3.0 Fluorometer, Life Technologies). Briefly, $1 \mu \mathrm{g}$ of DNA was sheared into $500 \mathrm{bp}$ fragments on a Covaris M220 focused ultra-sonicator (Covaris Inc) using SonoLabTM 7.1 software for 200 cycles/burst, 20.0 Duty factor, 50.0 Peak power, in screw-cap microtubes. After shearing, the DNAs were end-repaired using EndPrep master mix and ligated to indexed adaptors. The adaptor-ligated genomic DNAs were size selected with AMPure-beads using the gel free protocol described in the NEBNext Ultra DNA Library Prep manual. Size-selected DNAs were amplified by PCR to selectively enrich for fragments that have adapters on both ends. Final amplified libraries were run on an Agilent bioanlyzer DNA 2100 (Agilent, Santa Clara, CA, USA) to determine the average fragment size and to confirm the presence of DNA of the expected size range. The libraries were pooled in equimolar concentration and loaded onto a flowcell for cluster formation and sequenced on an Illumina MiSeq platform. The libraries were sequenced from both ends of the molecules to a total read length of $250 \mathrm{nt}$ long from each end.

The raw bcl files were converted into demultiplexed compressed fastq files using Casava 1.8.2 (Illumina). FASTAQ (a text-based format for storing nucleotide sequence) files were trimmed using the computer program Sickle, a windowed adaptive trimming tool for FASTQ files using quality (https://github.com/najoshi/sickle). The reads were filtered by standard parameters (quality reads-20, cutoff length-20). The reads containing " $\mathrm{N}$ " were discarded. Reads were assembled into mitochondrial DNA molecules using the CLC Genomics Workbench 20.0.4 computer program (QIAGEN; https://digitalinsights.qiagen.com/). The contig was aligned to the reference mitochondrial genome sequence using BLASTN (http://www.ncbi.nlm.nih.gov). For detection of SNP (single nucleotide polymorphism) and Indels (insertion/ deletion) computer programs Mafft and Blast were used [11] [12].

\section{Results and Discussion}

Mitochondrial genomes of the members of superclass Hexapoda are $14-16$ $\mathrm{kb}$ in length and typically comprise 37 genes, 13 protein-coding genes (PCGs), 22 transfer RNA (tRNAs) genes and 2 ribosomal RNA (rRNAs) genes [8]. A phylogenetic tree of mitochondrial COI gene fragments (608 bp) from the 65 H. halys specimens collected across west Georgia was constructed (Figure 1). Thirty-one different haplotypes from GenBank [3] [7] [15] were used to construct the phylogenetic tree all Georgian $H$. halys samples were concentrates around the $\mathrm{H} 1$ haplotype, which is native to China.

This research also aimed to determine a complete mitochondrial DNA sequence for the $H$. halys (Stal) specimens collected in Georgia. The complete mitochondrial DNA sequence of only the $H$. halys $\mathrm{H} 22$ (native to Korea) haplotype is known (NC_013272.1) [8], and it contains two repeat regions: repeat 1, 15,178 - 15,469 bp and repeat 2, 15,638 - 16,513 bp. The complete mitochondrial DNA sequence of an $H$. halys specimen from Samegrelo, Georgia (H1 haplotype, HGS) 
was sequenced in this study, and the sequence has been submitted to GenBank (LC579925). The mitochondrial DNA of HGS has a length of 15,478 bp. Using the sequence of the $\mathrm{H} 22$ haplotype as a reference, 62 SNPs, three inversions and four single $\mathrm{T}$ insertions were identified in the mitochondrial DNA of HGS. Out of 18 genes in the HGS mitochondrial DNA, 60 SNPs and four insertions were identified in two tRNA and one rRNA genes. Nine of these SNPs resulted in amino acid substitutions (Table 1, Table 2). The detection of these SNPs revealed many other polymorphic sites beyond the COI gene, which can be used to detect new haplotypes. The mitochondrial DNA of HGS also contains one repeat region, $15,182-15,473 \mathrm{bp}$.

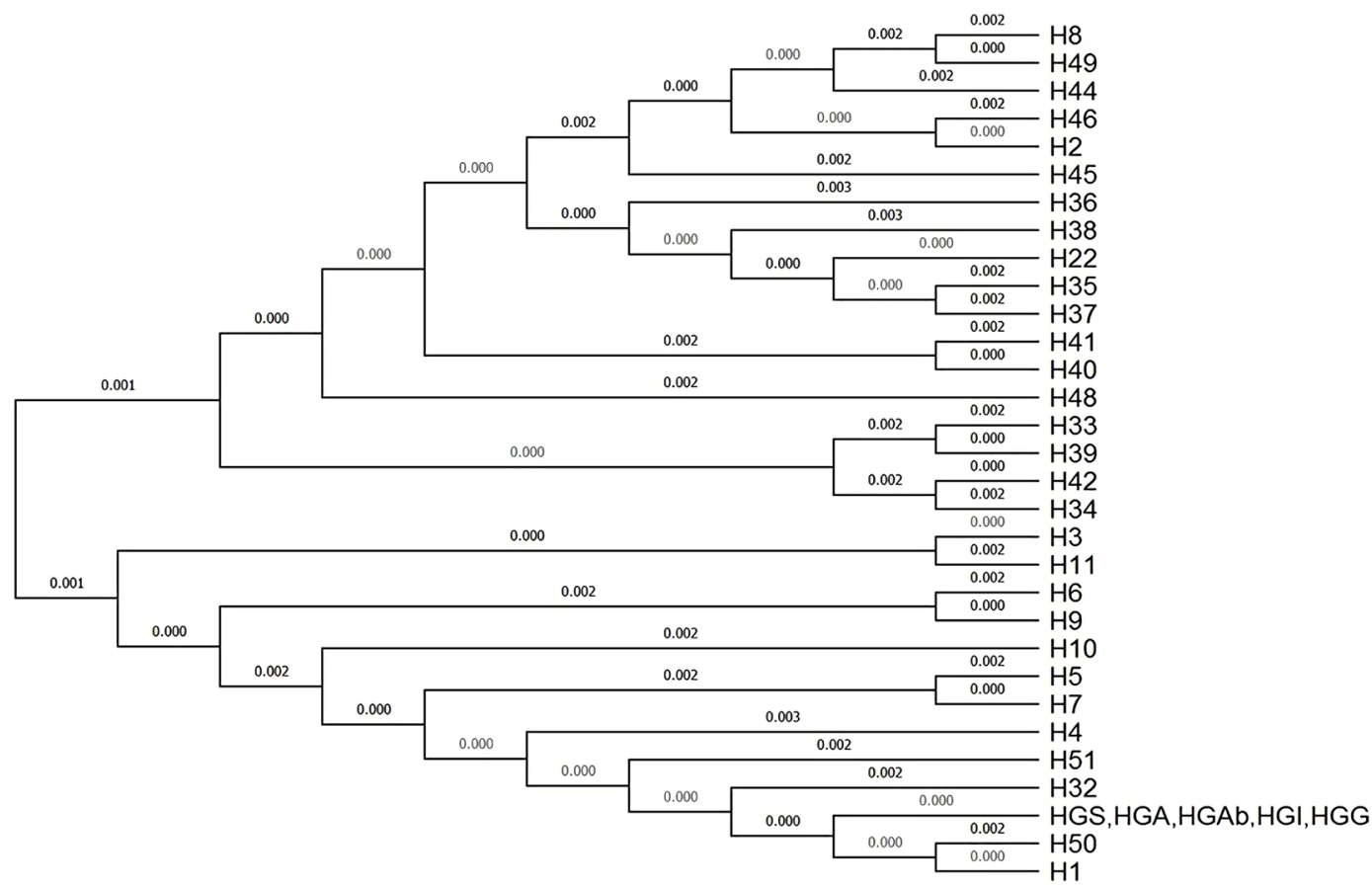

Figure 1. Mitochondrial genome (cytochrome c oxidase I subunit gene fragment) phylogeny of the $\mathrm{Ha}$ lyomorpha halys accessions.

The evolutionary history was inferred by using the Maximum Likelihood method and Tamura-Nei model (Tamura and Nei, 1993). The following GenBank accessions were used for the analyses: H1_KY710348; H2_KX017350; H3_KM401490; H4_KF273383; H5_KF273384; H6_KF273385; H7_KF273386; H8_KY710311; H9_KF273388; H10_KF273389; H11_KF273390;

H22_NC_013272; H32_KY710274; H33_KY710272; H34_KX01733;

H35_KX017376; H37_KX017355; H39_KX017357; H36_KX017360;

H38_KX017337; H40_KY710346; H41_KY710323; H42_KY710424;

H44_KY710294; H45_KM401490; H46_KY710433; H48_KY710336;

H49_KY710398; H50_KX017388; H51_KX017394.

Georgian $H$. halys samples by collection region: HGS, Samegrelo; HGI, Imereti; HGG, Guria; HGA, Adjara; HGAb, Abkhazia. 
Table 1. SNPs in the mitochondrial DNA of $H$. halys (H1 haplotype) spread in Georgia.

\begin{tabular}{|c|c|c|c|c|}
\hline $\begin{array}{l}\text { Nucleotide positions according } \\
\text { to H22 haplotype of } H \text {. halys } \\
\text { (NC_013272.1) }\end{array}$ & Locus & $\begin{array}{l}\mathrm{H} 22 \\
\text { haplotype }\end{array}$ & HGS_Samegrelo & $\begin{array}{l}\text { Amino acid } \\
\text { substitution }\end{array}$ \\
\hline 462 & Gene $N D 2$ & G & A & V-I \\
\hline 492 & Gene ND2 & $\mathrm{C}$ & $\mathrm{T}$ & Syn \\
\hline 509 & Gene $N D 2$ & G & A & Syn \\
\hline 530 & Gene ND2 & A & G & Syn \\
\hline 699 & Gene ND2 & A & G & $\mathrm{M}-\mathrm{V}$ \\
\hline 758 & Gene ND2 & $\mathrm{C}$ & $\mathrm{T}$ & Syn \\
\hline 833 & Gene $N D 2$ & G & A & Syn \\
\hline 1049 & Gene ND2 & $\mathrm{T}$ & $\mathrm{C}$ & Syn \\
\hline 1789 & Gene $C O X 1$ & G & A & Syn \\
\hline 1777 & Gene $C O X 1$ & $\mathrm{C}$ & $\mathrm{T}$ & Syn \\
\hline 3368 & Gene $C O X 2$ & A & G & Syn \\
\hline 3494 & Gene $C O X 2$ & A & G & Syn \\
\hline 3936 & Gene $A T P 8$ & $\mathrm{C}$ & $\mathrm{T}$ & S-L \\
\hline 4115 & Gene $A P T 6$ & G & A & V-M \\
\hline 4290 & Gene $A P T 6$ & $\mathrm{~T}$ & C & Syn \\
\hline 4831 & Gene $C O X 3$ & A & G & Syn \\
\hline 5038 & Gene $C O X 3$ & $\mathrm{~T}$ & $\mathrm{C}$ & Syn \\
\hline 5236 & Gene $C O X 3$ & $\mathrm{R}$ & A & Syn \\
\hline 5242 & Gene $C O X 3$ & $\mathrm{~T}$ & $\mathrm{C}$ & Syn \\
\hline 5558 & Gene ND3 & A & G & Syn \\
\hline 5568 & Gene $N D 3$ & A & G & $\mathrm{M}-\mathrm{V}$ \\
\hline 5651 & Gene $N D 3$ & $\mathrm{C}$ & $\mathrm{T}$ & Syn \\
\hline 5968 & $t R N A-A r g$ & $\mathrm{~T}$ & $\mathrm{C}$ & \\
\hline 6371 & Gene ND5 & A & G & Syn \\
\hline 6587 & Gene ND5 & $\mathrm{C}$ & $\mathrm{T}$ & Syn \\
\hline 6771 & Gene ND5 & A & G & F-S \\
\hline 6893 & Gene ND5 & A & G & Syn \\
\hline 6941 & Gene ND5 & $\mathrm{T}$ & $\mathrm{C}$ & Syn \\
\hline 6956 & Gene $N D 5$ & G & A & Syn \\
\hline 7006 & Gene ND5 & A & G & Syn \\
\hline 7134 & Gene ND5 & G & $\mathrm{T}$ & T-N \\
\hline 7847 & Gene ND5 & $\mathrm{C}$ & $\mathrm{T}$ & Syn \\
\hline 8344 & Gene $N D 4$ & A & $\mathrm{T}$ & Syn \\
\hline 8383 & Gene $N D 4$ & $\mathrm{~T}$ & $\mathrm{C}$ & Syn \\
\hline 8527 & Gene $N D 4$ & G & $\mathrm{A}$ & Syn \\
\hline 9546 & Gene $N D 4 L$ & $\mathrm{~T}$ & C & Syn \\
\hline 9833 & Gene $N D 6$ & $\mathrm{~T}$ & $\mathrm{C}$ & Syn \\
\hline 10,116 & Gene ND6 & A & $\mathrm{C}$ & I-L \\
\hline 10,356 & Gene $C Y T B$ & $\mathrm{~T}$ & $\mathrm{C}$ & Syn \\
\hline 10,612 & Gene $C Y T B$ & A & G & Syn \\
\hline 10,617 & Gene $C Y T B$ & $\mathrm{C}$ & $\mathrm{T}$ & Syn \\
\hline
\end{tabular}




\section{Continued}

\begin{tabular}{ccccc}
\hline 10,656 & Gene $C Y T B$ & G & A & Syn \\
11,019 & Gene $C Y T B$ & G & A & Syn \\
11,046 & Gene $C Y T B$ & G & A & Syn \\
11,088 & Gene $C Y T B$ & C & T & Syn \\
11,779 & Gene $N D 1$ & G & A & Syn \\
11,791 & Gene $N D 1$ & G & A & Syn \\
12,129 & Gene $N D 1$ & T & C & I-V \\
12,199 & Gene $N D 1$ & A & G & Syn \\
12,223 & Gene $N D 1$ & A & G & Syn \\
12,319 & Gene $N D 1$ & G & A & Syn \\
12,352 & Gene $N D 1$ & G & A & Syn \\
13,715 & $r R N A-16 S$ & G & A & \\
14,701 & $r R N A-12 S$ & T & C & \\
14,956 & Intergenic region & G & A & \\
\hline & $r R N A-12 S$ & & & \\
\hline
\end{tabular}

Table 2. Insertions and inversions in the mitochondrial DNA of $H$. halys (H1 haplotype) spread in Georgia.

\begin{tabular}{cccc}
\hline $\begin{array}{c}\text { Nucleotide positions According } \\
\text { to H22 haplotype of } H \text {. halys } \\
\text { (NC_013272.1) }\end{array}$ & Locus & H22 haplotype & HGS_Samegrelo \\
\hline 6077 & tRNA-Asn & - & $+1 \mathrm{~T}$ \\
6233 & $t R N A-$ Phe & - & $+1 \mathrm{~T}$ \\
14,199 & $r R N A-12$ S ribosomal $R N A$ & - & $+1 \mathrm{~T}$ \\
14,627 & $r R N A-12 S$ ribosomal $R N A$ & - & $+1 \mathrm{~T}$ \\
$15,309-15,314$ & Repeat region & - & 6 bp Invertion \\
$15,317-15,318$ & Repeat region & - & 2 bp Invertion \\
$15,382-15,387$ & Repeat region & - & 6 bp Inversion \\
\hline
\end{tabular}

\section{Conclusion}

This study represents the first attempted genetic study of the spread of $H$. halys in Georgia. Notably, only the H1 haplotype of Chinese origin was found to be widespread in Georgia. These results are consistent with the findings of Musolin et al. [5], who reported that the $H$. halys that distributed in Abkhazia, Georgia, was spread from Italy (an H1 haplotype dominant area) via Russia. The complete mitochondrial DNA sequence of HGS was determined (LC579925) in this study and its length was found to be $15,478 \mathrm{bp}$.

\section{Data Availability Statement (DAS)}

Cytochrome oxidase I sequences are openly available in GenBank at: https://www.ncbi.nlm.nih.gov/nuccore/?term=LC581788\%3ALC581792\%5BAC CN\%5D The mitogenome data supporting this study are openly available in 
GenBank at: https://www.ncbi.nlm.nih.gov/nuccore/LC579925. The associated BioProject, SRA, and BioSample accession numbers are:

https://www.ncbi.nlm.nih.gov/bioproject/PRJNA678533, https://www.ncbi.nlm.nih.gov/sra/PRJNA678533, and SAMN16805180, respectively.

\section{Authors' Contribution Statement}

TB and MG conceived and designed research. TS and NT conducted experiments. NK, TB, and MG analyzed data. MG, TB, and NK wrote the manuscript. All authors read and approved the manuscript.

\section{Acknowledgements}

This work was supported by the Shota Rustaveli National Science Foundation of Georgia (SRNSFG) and the National Food Agency of Georgia (grant number: NFA-SRNSFG-18-403).

\section{Conflicts of Interest}

The authors declare no conflicts of interest regarding the publication of this paper.

\section{References}

[1] Callot, H. and Brua, C. (2013) Halyomorpha halys (Stal, 1855), la Punaise diabolique, nouvelle espece pour la faune de France (Heteroptera Pentatomidae). L'Entomologiste, 69, 69-71.

[2] Cesari, M., Maistrello, L., Ganzerli, F., Dioli, P., Rebecchi L. and Guidetti, R. (2014) A Pest Alien Invasion in Progress: Potential Pathways of Origin of the Brown Marmorated Stink Bug Halyomorpha halys Populations in Italy. Journal of Pest Science, 88, 1-7. https://doi.org/10.1007/s10340-014-0634-y

[3] Cesari, M., Maistrello, L., Piemontese, L., Bonini, R., Dioli, P., Lee, W., Park, G.G., Partsinevelos, G.K., Rebecchi, L. and Guidetti, R. (2018) Genetic Diversity of the Brown Marmorated Stink Bug Halyomorpha halys in the Invaded Territories of Europe and Its Patterns of Diffusion in Italy. Biological Invasions, 20, 1073-1092. https://doi.org/10.1007/s10530-017-1611-1

[4] Gapon, D.A. 2016. First Records of the Brown Marmorated Stink Bug Halyomorpha halys (Stål, 1855) (Heteroptera, Pentatomidae) in Russia, Abkhazia, and Georgia. Entomological Review, 96, 1086-1088. https://doi.org/10.1134/S001387381608011X

[5] Musolin, D.L., Konjević, A., Karpun, N.N., Protsenko, V.Y., et al. (2018) Invasive Brown Marmorated Stink Bug Halyomorpha halys (Stål) (Heteroptera: Pentatomidae) in Russia, Abkhazia, and Serbia: History of Invasion, Range Expansion, Early Stages of Establishment, and First Records of Damage to Local Crops. ArthropodPlant Interactions, 12, 517-529. https://doi.org/10.1007/s11829-017-9583-8

[6] Xu, J., Fonseca, D.M., Hamilton, G.C., Hoelmer, K.A. and Nielsen, A.L. (2014) Tracing the Origin of US Brown Marmorated Stink Bugs, Halyomorpha halys. Biological Invasions, 16, 153-166. https://doi.org/10.1007/s10530-013-0510-3

[7] Lee, W., Guidetti, R., Cesari, M., Gariepy, T.D., Park, Y.L. and Park, C.G. (2018) Genetic Diversity of Halyomorpha halys (Hemiptera, Pentatomidae) in Korea and Comparison with COISequence Datasets from East Asia, Europe, and North Ameri- 
ca. Florida Entomologist. 101, 49-54. https://doi.org/10.1653/024.101.0110

[8] Lee, W., Kang, J., Jung, C., Hoelmer, K., Lee, S.H. and Lee, S. (2009) Complete Mitochondrial Genome of Brown Marmorated Stink Bug Halyomorpha halys (Hemiptera: Pentatomidae), and Phylogenetic Relationships of Hemipteran Suborders. Molecules and Cells, 28, 155-165. https://doi.org/10.1007/s10059-009-0125-9

[9] Folmer, O., Black, M., Hoeh, W., Lutz, R. and Vrijenhoek, R. (1994) DNA Primers for Amplification of Mitochondrial Cytochrome C Oxidase Subunit I from Diverse Metazoan Invertebrates. Molecular Marine Biology and Biotechnology, 3, 294-299.

[10] Thompson, J.D., Gibson, T.J., Plewniak, F., Jeanmougin, F., and Higgins, D.G. (1997) The CLUSTAL_X Windows Interface: Flexible Strategies for Multiple Sequence Alignment Aided by Quality Analysis Tools. Nucleic Acids Research, 25, 4876-4882. https://doi.org/10.1093/nar/25.24.4876

[11] Katoh, K., Rozewicki, J. and Yamada, K.D. (2019) MAFFT Online Service: Multiple Sequence Alignment, Interactive Sequence Choice and Visualization. Briefings in Bioinformatics, 20, 1160-1166. https://doi.org/10.1093/bib/bbx108

[12] Altschul, S.F., Gish, W., Miller, W., Myers, E.W. and Lipman, D.J. (1990) Basic Local Alignment Search Tool. Journal of Molecular Biology, 215, 403-410. https://doi.org/10.1016/S0022-2836(05)80360-2

[13] Tamura, K. and Nei, M. (1993) Estimation of the Number of Nucleotide Substitutions in the Control Region of Mitochondrial DNA in Humans and Chimpanzees. Molecular Biology and Evolution, 10, 512-526.

[14] Kumar, S., Stecher, G., Li, M., Knyaz, C. and Tamura, K. (2018) MEGA X: Molecular Evolutionary Genetics Analysis across Computing Platforms. Molecular Biology and Evolution, 35, 1547-1549. https://doi.org/10.1093/molbev/msy096

[15] Gariepy, T.D., Haye, T., Fraser, H. and Zhang, J. (2014) Occurrence, Genetic Diversity, and Potential Pathways of Entry of Halyomorpha halys in Newly Invaded Areas of Canada and Switzerland. Journal of Pest Science, 87, 17-28.

https://doi.org/10.1007/s10340-013-0529-3 